\title{
Urinary Schistosomiasis in Communities around Kiri Lake, Shelleng Local Government Area, Adamawa State, Nigeria
}

\section{*11BIRMA, JS; ${ }^{1}$ CHESSED, G; ${ }^{2}$ SHADRACH, PA ; ${ }^{3}$ NGANJIWA, JI; ${ }^{4}$ YAKO, AB; ${ }^{5}$ VANDI, P; ${ }^{2}$ LAURAT, T.}

\author{
1. Federal Government Girls College, Yola, Adamawa State-Nigeria. \\ 2. Department of Zoology, Moddibo Adama University of Technology, P. M. B. 2076, Yola, Adamawa State- \\ Nigeria. \\ 3. Ramat Polytechnic, Maiduguri, Borno State, Nigeria. \\ 4. Department of Biological Sciences, Nassarawa State University, Keffi, Nassarawa State-Nigeria. \\ 5. Department of Science, Federal College of Education, Yola, Adamawa State-Nigeria. \\ *Corresponding author e-mail: $\quad$ godlychessed@gmail.com \\ Tel: +2348055583405
}

\begin{abstract}
The objectives of the study were to determine the prevalence of urinary schistosomiasis in the different communities, the intensity of infection, prevalence among gender and age groups and to relate infection with parent's occupation. A study on the prevalence of urinary schistosomiasis was conducted in four villages around Kiri Lake in Shelleng Local Government Area, Adamawa State, Nigeria. Two hundred and thirty two urine samples were collected from four primary school children randomly selected from within the four study communities. Overall, prevalence of urinary schistosomiasis was 48\% (111/232), with males recording $49 \%$ (69/142) and females $47 \%$ (42/90). The total mean egg count (MEC) was 8.3. There was no significant difference in prevalence between males and females $(\mathrm{P}>0.05)$. Prevalence was higher among age groups, with the 13-15 year old age group having the highest $62.96 \%(17 / 27)$ and the 4-6 year old age group had the least $37 \%$ (19/52). There was no statiscally significant difference in prevalence among the different age groups $(\mathrm{P}>0.05)$. Infection was also high among children of fishermen 59.09\% (13/22), followed by farmers' children $56.25 \%$ (45/80) and the least prevalence was among children of teachers $20 \%(3 / 15)$. Old Banjiram had the highest infection of $91 \%$ (21/23), while Kwadadai had the least $36.8 \%$ $(21 / 57)(\mathrm{P}<0.05)$. Old Banjiram and children in the $10-12$ years age group had the highest mean egg count of 10.6 and 9.4 respectively. The study reveals a high prevalence of urinary schistosomiasis. And therefore portable water source should be made functional in all communities surrounding the lake. While rehabilitation and repair of the existing water borehole system in the community should be effected as well as drilling new additional boreholes to serve their water needs. Commun JASEMity participatory health education on this neglected tropical disease in the area is needed on knowledge of the disease, the intermediate host and transmission pattern. Since school children harbour infection and are a source of infection of schistosomiasis in endemic communities, planning and provision for their treatment should be considered in control programmes. ( ) JASEM
\end{abstract}

http://dx.doi.org/10.4314/jasem.v21i1.14

Keywords: Schistosoma haematobium, Prevalence, Kiri lake, Socio-economic, School children, Nigeria.

Schistosomiasis is one of the most widespread of all human parasitic diseases, ranked second after malaria in terms of socio-economic and public health importance in the tropics (WHO, 2016a). The disease is endemic in 78 developing countries, infecting almost 240 million people worldwide, and more than 700 million people live in endemic areas. Twenty millions of these suffer severe consequences from the disease and 120 million are symptomatic and the rest are usually asymptomatic (Capron, et al., 2002; WHO, 2016a). Estimates show that at least 258 million people required preventive treatment for schistosomiasis in 2014. Ninety percent of those live in Africa (WHO, 2016b). Schistosomiasis leads to a chronic and debilitating ill health. (Enersen, 2015; Uneke, et al., 2010). The estimates for morbidity in affected populations are high especially in school children between the ages of 6-15 years; children that swim and play in nearby lakes and irrigation channels, women who carryout household chores like fetching water, washing clothes and cooking utensils, fishermen and irrigation workers who always make 
contact with water for leisure, recreation or as a result of their profession expose themselves to the intermediate hosts of the parasite (Okoli and Odaibo, 1999; WHO, 2010). Urogenital schistosomiasis is caused by Schistosoma haematobium and intestinal schistosomiasis by any of the following organisms: $S$. mansoni, S. japonicum, S.intercalatum and $\mathrm{S}$. mekongi (WHO, 2016b). The most common of all these are $S$. haematobium and $S$. mansoni which are more prevalent in African countries. In urinary schistosomiasis, there is the risk of terminal haematuria (blood in last drop of urine), dysuria (painful urination), bladder cancer or kidney problem, nutritional deficiencies and in children, growth retardation are well established (WHO, 2010). The economic and health effects of the disease should not be underestimated (WHO, 1997). In Nigeria, Unfortunately not much has been achieved in the control of urinary schistosomiasis in the country largely because the disease an occupational disease that affects people engaged in agricultural activities in rural and semi-rural areas. There is high risk of people becoming infected as a result of low literacy level, poverty, sub-standard hygiene and inadequate public infrastructure (Mufe, et al., 2005). Another important factor that has adversely affected control efforts is lack of scientific information on the disease in many rural communities among the high risk group's particularly school-aged children. The establishment of water resource development projects has been associated with outbreaks of schistosomiasis in many parts of Tropical Africa (WHO, 2010). Although the development of water resources is immensely beneficial to a developing country like Nigeria, which seeks to boost water supply and increase agricultural production to feed its growing population, evidence abounds to show that the planning, design and execution of such projects are often undertaken without considering their public health implications thereby spreading water related diseases such as schistosomiasis (Oladejo and Ofoezie, 2006; Akinwale, et al., 2010). In the present study, Kiri was selected for a comprehensive investigation. The objectives of the study were to determine the prevalence of urinary schistosomiasis in the different communities and the intensity of infection in terms of egg count $/ 10 \mathrm{ml}$ of urine, prevalence among gender and age groups and to relate infection with parent's occupation. Results obtained will help in disease control and will allow for comparison with other studies on urinary schistosomiasis from different regions.

\section{MATERIALS AND METHODS}

Study area and population: The Kiri Dam (9.6797 $\mathrm{N} ; 12.04^{\circ}$ E) is located in Shelleng Local Government Area (LGA) of Adamawa State, Northeastern Nigeria, damming the Gongola River. It is $11.2 \mathrm{~km}$ long; $20 \mathrm{~m}$ high zoned embankment with internal clay blanket. The reservoir built in 1982 has a capacity of 615 million $\mathrm{m}^{3}$ for hydroelectric generation, provision of water for irrigation of sugar cane for the Savannah Sugar Company (SSC); a large-scale sugar cane plantation and processing company set up as a joint venture between the Federal Government of Nigeria and the Commonwealth Development Corporation (CDC), London (USTDA, 2011). The major water supply to the dam is from Dadin Kowa dam in Gombe State, and it is a tributary to river Benue via River Gongola. Communities around the Kiri dam consists of clusters of compounds each surrounded by locally made mats and mud wall. The compounds are situated 50-100 metres away from the Dam. The main occupation of the people is farming, fishing, petty trading and nomadic Fulani criss-cross the area in their yearly cattle migration in search of pasture. Crop cultivated in the area include: beans, sweet potato, maize, millet, sorghum and guinea corn. The fishermen are mainly Kanakuru tribe. There are also other tribes, like the Lunguda, Bachama, Hausa, Bura, Jukun and Jenjo. The inhabitants come in contact with the dam on a daily basis for different purposes including fishing, bathing, washing and collecting water for domestic use. There is no health clinic and sanitary infrastructure such as safe water and latrines in the community which if present are poorly constructed. The only borehole available is inadequate and is controlled. In preference, the dam is used by residents for several purposes. As a result of poor sanitary infrastructure most people defaecate and urinate indiscriminately thereby contaminating the surrounding environment near the dam. With an open vegetation of shrubs and herbaceous plants much favoured by animals, the closeness of Savannah Sugar Company thus provides foliage environment for animals; the dam is conducive for the nomadic Fulani in the dry season and serves as a major campsite and stop-post for the nomads' North-South migration.

Ethical Clearance: The ethical clearance was obtained from the Ministry of Health, Adamawa State, Nigeria. Consent and approval was also obtained from the various village Heads and the Director, Primary Health Care, Shelleng LGA. Interactive sessions were held with all respondents and their parents; they were informed on the purpose 
of the study. Verbal consent was also obtained from participants before the study commenced.

Collection of Urine: Universal bottles were labelled and distributed to the children; they were instructed to collect urine between mid and last drop of their urine. The urine was collected between $12.00 \mathrm{pm}$ and $2.00 \mathrm{pm}$. This is the period of greatest egg output (Bradley, 1963). Information on age, gender, community, and parent's occupation were recorded for each participant. The urine samples were physically examined macroscopically, the colour was recorded before transporting to the laboratory for analysis (Cheesebrough, 2006).

Macroscopic and Microscopic Examination of Urine Sample: The urine sample was agitated by gentle inversion of the sample bottle; $10 \mathrm{ml}$ of urine sample was poured into a clean centrifuge tube and spun at 2,000 rpm for $5 \mathrm{~min}$. The supernatant was decanted, the sediment mixed by tapping and $0.15 \mathrm{ml}$ of urine applied on a clean, grease free slide with the aid of a pipette, covered with a cover glass and examined. Eggs were counted using the X10 and X40 objective lens (Iguh, 2010).

Data Analysis: SPSS statistical software was used to obtain frequencies. Chi-square test was used for comparing infection and determining the relationship between infection pattern, age and gender in the study area. Ninety five (95\%) confidence intervals were calculated for the prevalence.

\section{RESULTS AND DISCUSSION}

Out of the 232 primary school children examined for urinary schistosomiasis, 111 (47.8\%) were infected. The prevalence and intensity of the infection varied among the communities. Highest prevalence was recorded in Old Banjiram 91.3\% (21/23), followed by Talum 47.36\% (9/19), Kiri 45\% (60/133), while Kwadadai had the least prevalence of $36.84 \%$ (21/57) (Table 1); $X^{2}=21.745, \mathrm{df}=3, p<0.05$. The overall mean egg count (MEC) per $10 \mathrm{ml}$ of urine was 8.3, with a range of 2.1 to 10.6 among communities. Old Banjiram had the highest MEC of 10.6; the least MEC was in Talum (2.1).

Table 2 shows the prevalence of urinary schistosomiasis infection in relation to gender. The males had insignificant $(p>0.05)$ highest percentage (49\%), than the females $(47 \%)$. Males had a MEC of 9.1, while females had 7.5.

The overall age-related prevalence of urinary schistosomiasis is shown in table 3 . Children within the 13-15 years age group had the highest prevalence of $62.96 \%$ (17/27), followed by the $7-9$ years $49.35 \%$ (38/77) and 10-12 years $48.68 \%$ (37/76) respectively, while the 4-6 years old age group had the least prevalence of $36.54 \%$ (19/52). The prevalence of urinary schistosomiasis in the study increased with age of the children $\left(X^{2}=4.717, \mathrm{df}=3, P>0.05\right)$. Highest MEC was among 10-12 years age group, followed by 13-15 and 7-9 years age group having 9.1 and 8.6 eggs per $10 \mathrm{ml}$ urine respectively. The least being among 4-6 years with 6 MEC.

Table 4 shows the prevalence of urinary schistosomiasis in children in relation to the socioeconomic background to parents occupation. The study revealed that urinary schistosomiasis is wide spread in children from families of different occupational groups in the endemic communities. Pupils from families of fisher men and farmers had prevalence of $59.09 \%$ and $56.26 \%$ respectively, followed by those whose parents are traders $(29.4 \%)$. In all schools, children whose parents were teachers had the least prevalence of $20 \%$. Parents occupation did not affect the prevalence of urinary schistosomiasis in the children $\left(X^{2}=8.786, \mathrm{df}=4\right.$, $\mathrm{P}<0.05)$. Interestingly, MEC among children of teacher's was highest (10.3), followed by fishermen (9.7), farmer's (9.2), and the least was among trader's children (6.6).

Table 1: Prevalence of urinary schistosomiasis in children in communities around

Kiri lake, Shelleng LGA, Adamawa State.

\begin{tabular}{lccl}
\hline Community & No. examined & No. infected $(\%)$ & $*$ MEC \\
\hline Kiri & 133 & $60(45)$ & 7.9 \\
Talum & 19 & $9(47.36)$ & 2.1 \\
Kwadadai & 57 & $21(36.84)$ & 9.5 \\
Old Bajiram & 23 & $21(91.3)$ & 10.6 \\
Total & 232 & $111(47.8)$ & 8.3 \\
\hline
\end{tabular}

*MEC $=$ Mean egg count $/ 10 \mathrm{ml}$ of urine 
Table 2: Gender related prevalence of urinary schistosomiasis in children in communities around

Kiri lake, Shelleng LGA, Adamawa State.

\begin{tabular}{llll}
\hline Gender & No. examined & No. infected (\%) & $*$ MEC \\
\hline Male & 142 & $69(49)$ & 9.1 \\
Female & 90 & $42(47)$ & 7.5 \\
Total & $\mathbf{2 3 2}$ & $\mathbf{1 1 1}(\mathbf{4 7 . 8 )}$ & $\mathbf{8 . 3}$ \\
\hline
\end{tabular}

*MEG=Mean egg count/10 ml urine

Table 3: Age-related prevalence of urinary schistosomiasis in children in communities around Kiri lake, Shelleng LGA, Adamawa State.

\begin{tabular}{llll}
\hline Age group (Yrs) & No. examined & No. infected $(\%)$ & "MEC \\
\hline $4-6$ & 52 & $19(36.54)$ & 6 \\
$7-9$ & 77 & $38(49.35)$ & 8.6 \\
$10-12$ & 76 & $37(48.68)$ & 9.4 \\
$13-15$ & 27 & $17(62.96)$ & 9.1 \\
Total & 232 & $111(47.8)$ & 8.3 \\
\hline
\end{tabular}

*MEC=Mean egg count $/ 10 \mathrm{ml}$ urine

Table 4: Prevalence of urinary schistosomiasis in relation to parent's occupation

\begin{tabular}{llll}
\hline Occupation & No. examined & No. infected $(\%)$ & ${ }^{*}$ MEC \\
\hline Farmer & 80 & $45(56.25)$ & 9.2 \\
Fishermen & 22 & $13(59.09)$ & 9.7 \\
Teacher & 15 & $3(20.00)$ & 10.3 \\
Trader & 63 & $29(46.02)$ & 6.6 \\
Others & 52 & $21(40.38)$ & 8.6 \\
Total & 232 & $111(47.8)$ & .3 \\
\hline
\end{tabular}

*MEC=Mean egg count $/ 10 \mathrm{ml}$ urine

This study showed that urinary schistosomiasis has a high prevalence in communities around Kiri Lake; this could be ascribed to their proximity to the lake as corroborated by previous studies who reported that urinary schistosomiasis is widely distributed in areas where dams are situated including Nigeria (Betterton, et al., 1988; Anya and Okafor, 1989; Ofoezie, et al., 1997). Changes in the mode and patterns of production, including the development of new agricultural programs and cash cropping dependent upon regular water supplies, have often necessitated the establishment of irrigation schemes sustained by large and complex dams. Where this has occurred, the prevalence of schistosomiasis has increased, with the construction of water impoundments for irrigation and other purposes in areas of endemic water-related disease, intensifying community levels of infection and creating new areas of transmission (Chandiwana et al., 1988). Tayo, et al., (1980) and Hassan, et al., (2012), have suggested that a linear relationship exists between infection and individuals' water contact activities in northern Nigeria. The overall prevalence of $47.8 \%$ observed in Kiri lake communities was higher than the prevalence of 25.5\% reported by Ekejindu, et al., (2002), in some rural villages and farm settlements in South-eastern
Nigeria. The difference in prevalence rates may be influenced by peculiar ecological characteristics in the areas, levels of contact of individuals with water bodies and the degree of exposure to infective schistosome cercariae in different locations.

The prevalence of $S$. haematobium infection by communities showed that Old Banjiram had the highest infection of $91.3 \%$, followed by Talum $(47.36 \%)$, Kiri $(45 \%)$, while Kwadadai had the lowest infection rate of $36.84 \%$. This outcome could be associated with lack of portable sources of water to the communities and the proximity of Old Banjiram and Talum to Kiri Lake, which serves as a main reservoir and breeding site for the snail intermediate hosts. The populace of the two communities (Old Banjiram and Talum) uses water from Kiri lake for irrigation, fishing, swimming and domestic purposes more than the other two communities. Most parts of Kwadadai on the other hand, are farthest from the river and these results in lesser contact with the water source by the residents compared with those who live in the other two communities that are closer to the river. Kwadadai community also have access to other sources of water other than the river and this may have also accounted 
for the relatively low S. haematobium prevalence in the area.

Previous studies did not report a consistent pattern on gender-related prevalence of $S$. haematobium in Nigeria (Nnoruka, et al., 2002). In this study, a higher prevalence of $S$. haematobium infection was observed among males than females. The higher prevalence recorded among males could be attributed to their cultural habit of regular and longer contact with the water body which serves as the breeding site of the disease vectors among the male folks through farming and swimming than their female counterparts who are restricted by socio-cultural factors from swimming in the locally available river and ponds. This finding differs from a previous report by Anya and Okafor (1986) on prevalence of S. haematobium infection in females, but was, however, similar to other published findings by Dunah and Bristone (2000).

Infection was highest among subjects in the 13-15 year age group $(62.96 \%)$ with a gradual decrease. This result is similar to a previous finding by Ekejindu, et al., (2002) in a study in southern Nigeria; however, it was different from previous reports by Ukpai and Ezeike (2002), from other locations which indicated highest prevalence in the 5-10 year age group. The variation in the prevalence rate in different age groups from various study areas may be attributed to characteristics of the natural environment, water contact patterns of the children, and physico-chemical characteristics of locally available water influencing snail breeding in different ecological areas. Other studies by Tayo, et al., (1980); Kvalsvig and Schutle, (1986), revealed age groups to be at risk of acquiring infection. Some workers observed that adult males are usually involved in occupations such as fishing and farming that expose them to the intermediate hosts.

The children's socio-economic background taking into consideration their parent's or guardian's occupation showed that those from families involved in fishing and farming activities had the highest prevalence. This was probably because they follow their parents to farms or river and assist them after school. Okafor (1986), reported that farmer's bath in the fresh water, streams and or pools near their farms after each day's work. In the study population, most fishermen and farmers were ignorant of the mode of transmission of the disease and so they might be unaware of the implication of these activities in the lake in the transmission of the disease and even the few that did know seem to neglect it (Emejulu, 1994).
Children of trader's were next to fishermen and farmers' children in prevalence of infection, with prevalenvce of $46.02 \%$. Most members of this group were also ignorant and so may suffer the same fate as the farmers' children. The children of teachers and civil servants' were the least infected, an indication of their awareness and better personal hygiene practices.

The communal life in the study community is such that domestic activities like washing of clothes and utensils and fetching of water are the sole responsibilities of the children. Swimming had the greatest risk followed by fetching of water. During this study, most school children were also observed swimming in the lake. They do this because they want to catch fun or cool off the heat during high day-time temperatures. This was probably the cause of the high prevalence recorded in them. Wilkins (1987), stressed that recreational use of water for swimming and playing is usually of greater importance to younger children. Such activity might carry a high risk of infection as it often involves much of the body being in contact with water for longer periods of time.

In the study, we observed that the highest intensity of infection was among males. Furthermore, children in the 10-12 years age group exhibited higher mean egg count than the other age groups. Previous studies reported that in endemic, untreated populations, the prevalence and intensity of urinary schistosomiasis is usually higher among this age group (SousaFigueiredo, et al., 2009).

Conclusion: Our observation showed a high prevalence of urinary schistosomiasis in the study population and that children harbour infection with urinary schistosomiasis, and are therefore a source of transmission in endemic communities. Health education campaign on the mode of transmission, risks of infection with urinary schistosomiasis and public health implications of poor sanitary behaviour is necessary. Provision of motorized boreholes would contribute to the reduction of human activities at the lake and hence schistosomiasis. Mass treatment programme, through distribution and use of praziquantel is needed to stem the transmission and morbidity of the disease in the study area.

Acknowledgements: We acknowledge Staff of Specialist Hospital, Yola for allowing the use of their laboratory. Our gratitude to Shelleng LGA Primary Health Care Department, Education Secretary's for Shelleng LGA and Primary School Headmasters in the study area. 


\section{REFERENCES}

Akinwale, OP; Kane, RA; Rollinson, JR; Stothard, JR; Ajayi, MB; Akande, DO; Ogungbemi, MO; Duker, C; Gyang, PV; Adeleke, MA (2010). Molecular approaches to the identification of Bulinus species in South-West Nigeria and observations on natural snail infections with Schitosomes. J. Helminthol. 85(3): 283-293.

Anya, AO; Okafor, FC (1986). Prevalence of Schistosoma haematobium infections in Anambra State, Nigeria. Bull. de Ins. Fondamental de Afrique Norie. 46: 322-332.

Betterton, C; Ndifon, GT; Bassey, SE; Tan, RM; Oyeyi, T (1988). Schistosomiasis in Kano State, Nigeria: human infections near dam sites and the distribution and habitat preferences of potential snail intermediate hosts. Ann. Trop. Med. Parasitol. 82: 561-570.

Bradley, DJ (1963). A Quantitative approach to Bilharzia. East Afr. Med. J. 49 (5): 240 - 249.

Capron, A; Riveau, U (2002). Vaccine development against schistosomiasis from concepts to clinical trials. British Med. Bull. 62: 139-148.

Cheesbrough, M (2006). Medical Laboratory Manual for Tropical Countries. $2^{\text {nd }}$ Ed. Cambridge University Press, London, p.323-341.

Dunah, CS; Bristone, B (2000). The prevalence of Schistosoma haematobium among primary school pupils in Mayo-Belwa Local Government Area of Adamawa State, Nigeria. Nig. J. Parasitol. 21: 15-20.

Ekejindu, IM; Ekejindu, GOA; Agbai, A (2002). Schistosoma haematobium infection and nutritional status of residents in Ezi-Anam, A riverine area of Anambra State, South-Eastern Nigeria. Nig. J. Parasitol. 23: 131-138.

Emejulu, CA (1994). Epidemiology of urinary Schistosomiasis in Agulu lake Area of Anambra Stae, Nigeria. M.Sc Thesis, Department of Zoology, University of Nigeria, Nsukka, pp. 96.

Enersen, OD (2010). Theodore Maximillian Bilharz. http://www.whonameedit.com/doctor.cfm/2829.h tml. Accessed $23^{\text {rd }}$ April, 2015.

Hassan, AO; Amoo, AOJ; Akinwale, OP; DejiAgboola, AM; Adeleke, MA; Gyang, PV;
Oluwadun, A (2012). Human water contact activities and urinary schistosomiasis around Erinle and Eko-ende dams. Global Adv. Res. J. Med. Sci. 1(4): 077-084.

Kvalsvig, JD; Schutte, CH (1986). The role of human water contact patterns in the transmission of Schistosomiasis in an informal settlement near a major industrial area. Ann. Trop. Med. Parasitol. 80(1): 13-26.

Mufe, MA; Von-Stamm, T; Utzinger, J; Goram, KN (2005). Control of urinary schistosomiasis: an investigation into the effective use of questionnaires to identify high-risk communities and individuals in Niger State, Nigeria. Trop. Med. Intl. Hlth. 5(1): 53-63.

Nnoruka, VC; Anya, AO; Okafor, FC (2002). Epdemiological studies of urinary schistosomiasis in Imo State: III. Physicochemical characteristics of transmission sites in the North-West. Nig. J. Parasitol. 23: 119-124.

Okoli, EI; Odaibo, AB (1999). Urinary schistosomiasis among school children in Ibadan, an urban community in southern Nigeria. Trop. Med. Intl. Hlth. 4(4): 308-15.

Ofoezie, IE; Asaulu, SO; Christensen, NO; Madsen, H (1997). Patterns of infection with Schistosoma haematobium in lakeside resettlement communities at the Oyan reservoir in Ogun State, south-western Nigeria. Ann. Trop. Med. Parasitol. 91: 187-97.

Oladejo, SO; Ofoezie, IE (2006). Unabated schistosomiasis transmission in Erinle river dam, Osun State, Nigeria: evidence of neglect of environmental effects of development Projects. Trop. Med. Intl. Hlth. 11(6): 845-850.

Okafor, FC (1986). The ecophysiology and biology of the snail host of Schistosoma heamatobium disease in Anambra State, Nigeria. PhD. Thesis, Department of Zoology, University of Nigeria (UNN), Nsukka, p.287.

Sousa-Figueiredo, JC; Basáñez, MG; Khamis, IS; Garba, A; Rollinson, D; Stothard, JR (2009). Measuring morbidity associated with urinary schistosomiasis: assessing levels of excreted urine albumin and urinary tract pathologies. PLoS Negl. Trop. Dis. 3(10): 526.

doi:10.1371/journal.pntd.0000526. 
Tayo, MA; Pugh, RNH; Bradley, AK (1980). Malumfashi endemic disease research project. XI. Water contact activities in the Schistosomiasis study Area. Ann. Trop. Med. Parasitol. 74: 347-354.

Ukpai, OM; Ezeike, AC (2002). The prevalence of urinary schistosomiasis among primary school children in Aguata LGA Anambra State, Nigeria. Nig. J. Parasitol. 23: 139-144.

Uneke, C; Ugwuok-Adibuah, S; Nwakpu, K; Ngwu, B (2010). An assessment of Schistosoma

haematobium infection and Urinary tract bacterial infection amongst school children in rural eastern Nigeria. Intl. J. Lab. Med. 4: 1.

United States Trade and Development Agency (2011). Princeton energy resources international (peri). Feasibility study for the Nigeria: Kiri dam hydroelectric power plant. Task J Report: Final Report.

www.perihq.com/TDAReports/KiriDam_FINAL . Accessed $20^{\text {th }}$ June, 2015.

Wilkins, HA (1987). The Epidemiology of Schistosome Infections in Man. In: The Biology of Schistosomes from Genes to Latrines. Rollinson, D. and Simpson, J. (Eds). Academy Press, London, p.379-397.
WHO (1997). Meeting on strategies for the development of a schistosomiasis vaccine. WHO/TDR/SCH/VAC-DEV/91.3.

WHO (2010). Intermediate hosts of schistosomiasis and food borne trematode infections. Freshwater Snails.

http://www.who.int/water_sanitation_health/reso urces/vector. Accessed 20 $0^{\text {th }}$ January, 2015.

WHO (2016a). Schistosomiasis.

http://www.who.int/schistosomiasis/en. Accessed $29^{\text {th }}$ June, 2016.

WHO (2016b). Schistosomiasis.

http://www.who.int/mediacentre/factsheets/fs115/en/. Accessed $16^{\text {th }}$ November, 2016. 